\title{
Determination and Safety Evaluation of Difenoconazole Residues in Apples and Soils
}

\author{
Cong Guo • Jian-zhong Li • Bao-yuan Guo • \\ Hui-li Wang
}

Received: 11 March 2010/Accepted: 17 August 2010/Published online: 24 September 2010

(C) Springer Science+Business Media, LLC 2010

\begin{abstract}
Difenoconazole was a triazole fungicide with proven bio-efficacy which leads to morphological and functional changes in the fungal cell membrane. In this work, field trials were conducted in three apple orchards. Sampling methods were improved in both the terminal residual and dissipation experiments. Residual data were analyzed and results showed that, at both recommended rates with 3 times applications and 1.5-folds of recommended rates with 4 times applications, the preharvest intervals (PHIs) of difenoconazole in apples were 6-7 days. The $\mathrm{DT}_{50}$ of difenoconazole in apples and soils were $6.3-10.2$ and 9.6-68.4 days, respectively. $\mathrm{The}^{\mathrm{DT}} \mathrm{90}_{90}$ them were $26.2-40.6$ and 45.6-216.3 days, respectively.
\end{abstract}

Keywords Difenoconazole $\cdot$ Residual $\cdot$ PHI $\cdot$ Apple $\cdot$ Soil

The complex factors such as $\mathrm{pH}$, temperature, meteorological, microorganism of soil and ground water are different from place to place (Walker et al. 2001). It is not sufficient to evaluate a pesticide environment safety on just one kind of a crop or in just one single field place. Especially for the large area countries such as China, Canada and USA, the national standards of a pesticide usage such as the maximum residue limit (MRL) regulations and the preharvest intervals (PHIs) should take full account of the dietary habits of their people,

C. Guo · J. Li $(\bowtie) \cdot$ B. Guo $\cdot$ H. Wang

Research Center for Eco-Environmental Sciences,

Chinese Academy of Sciences, 100085 Beijing, China

e-mail: sinic_kuo@163.com

C. Guo

Chinese Institute of Geological Environmental Monitoring,

100081 Beijing, China the climate of food production area (Philippe et al. 2007) and the length of growth cycle of crops.

Belonging to $14 \alpha$-demethylation inhibitors, difenoconazole is a systemic triazole fungicide that controls a broad spectrum of foliar, seed and soil-borne diseases caused by Ascomycetes, Basidiomycetes and Deuteromycetes in cereals, soya, rice, grapes, pome fruit, stone fruit, potatoes, sugar beet and several vegetable and ornamental crops (Ellen et al. 1997). In some previous studies, the dissipation behavior of difenoconazole in apple leaves, grass, apple orchard soils, Chinese cabbage and its growth soil were examined (Jacob and Werner 1996; Ellen et al. 1997; Wang et al. 2008). It was found that in apple orchard, difenoconazole in soil was most derived from falling leaves and centered in the soil layer of $0-10 \mathrm{~cm}$. It was also found that difenoconazole followed sigrnoidal degradation kinetics in a silt loam soil and its residue had a long persistence. However, those studies were not comprehensive and representative; more studies were needed to evaluated environmental safety of difenoconazole.

In this study, field experiments were conducted in three places, namely Xiaoxian (Anhui province), Daxing (Beijing) and Hangzhou (Zhejiang province). These places were the representative production areas of apples in China. The physicochemical properties of the three soils were qualitatively and quantitatively analyzed, the meteorological conditions in the experimental period had been recorded. The terminal residual experiments were conducted on apples to detect the PHIs of difenoconazole on apples; the residual experiments were conducted both on apples and soils to research the dissipations of difenoconazole. Coupled with an improvement on the sampling method and the soil physicochemical properties test, the residual data were fitted with the simple first-order (SFO) kinetics model to depict the dissipation behaviors of difenoconazole. 


\section{Materials and Methods}

Difenoconazole (CAS No. 119446-68-3, purity: 97.5\%) and its commercial formulation (10\% Wettable Powder (WP) of difenoconazole) were got from Beijing organic agriculture technology center (China). HPLC grade ethyl acetate, florisil columns were purchased from Dikma (Dikma, China). All other chemicals were of analytical grade were purchased from Beijing Chemical Works (China).

Regulated by Institute for the Control of Agrochemicals, Ministry of Agriculture (ICAMA), PHI was the time period (in days) required for dissipation of the initial deposits after several times spraying at some intervals of time to below the MRL. Specifically, the residues of the three continuous samples after PHI should below the MRL. In this study, the terminal residue experiments were conducted in three places (Xiaoxian, Daxing and Hangzhou) to evaluate the PHIs of difenoconazole in apples.

The spraying action should stop once the medicated solution saturated and dropped from the trees (ICAMA), therefore, the application dosage measured not by the active ingredient per hectare (a.i./ha) but by active ingredient weight per liter $(\mathrm{mg} / \mathrm{kg})$. In this study, difenoconazole 10\% WP was applied at 66.7 and $100 \mathrm{mg} / \mathrm{kg}$ water solutions at 24, 16, 8 and 0 days (4 times) before harvest, 16, 8 and 0 days ( 3 times) before harvest, respectively. Each treatment including the untreated control had three replications in the randomized separate plots.

Xiaoxian, Daxing and Hangzhou were apple production region; the field trials were conducted in June of 2008. There was no history of difenocolazole application in these experiment areas. Three replicates and one control plots with a total area of $400 \mathrm{~m}^{2}$ (about 36 trees) were set in each trial.

Application was conducted by hand with a manual knapsack sprayer (Jacto HD400) at 4 kilogram-force (kgf)/ $\mathrm{cm}^{2}$ working pressure. Difenocolazole 10\% WP was applied in crops and soils at the dosage of $100 \mathrm{mg} / \mathrm{kg}$, which was 1.5 times higher than the recommended dosage. The physicochemical properties of the six soils were analyzed and listed in Table 1.

For the sample cleanup, a florisil solid-phase extraction (SPE) cartridge (1 g, Dikma, China) was preconditioned with $5 \mathrm{~mL}$ of acetone followed by $5 \mathrm{~mL}$ of hexane. Acetonitrile $(50 \mathrm{~mL})$ extract was evaporated to near dryness (at $43^{\circ} \mathrm{C}$ ), redissolved with $2 \times 3 \mathrm{~mL}$ hexane, residue was loaded into the cartridge and the effluent was discarded. The cartridge was eluted with $6 \mathrm{~mL}$ acetone-hexane (1:2) and dried under a gentle stream of nitrogen. The residue was re-constituted in $2 \mathrm{~mL}$ ethyl acetate and filtered through a $0.45 \mathrm{~mm}$ filter before GC analysis.
Table 1 Physicochemical characterisation of the three soils

\begin{tabular}{llll}
\hline Origin of the soil & Xiaoxian & Daxing & Hangzhou \\
\hline Longitude & $116^{\circ} 56^{\prime} 9^{\prime \prime} \mathrm{E}$ & $116^{\circ} 24^{\prime} 49^{\prime \prime} \mathrm{E}$ & $120^{\circ} 4^{\prime} 38^{\prime \prime} \mathrm{E}$ \\
Latitude & $34^{\circ} 9^{\prime} 52^{\prime \prime} \mathrm{N}$ & $39^{\circ} 37^{\prime} 9^{\prime \prime} \mathrm{N}$ & $30^{\circ} 17^{\prime} 56^{\prime \prime} \mathrm{N}$ \\
pH (suspended 2:5 in water) & 7.78 & 8.01 & 5.73 \\
Total organic C content $(\%)$ & 1.1 & 1.3 & 1.4 \\
Clay $(\%) D<0.002 \mathrm{~mm}$ & 11.1 & 21.4 & 9.2 \\
Silt $(\%)$ & 37.2 & 16.1 & 37.9 \\
$\quad 0.002<D<0.05 \mathrm{~mm}$ & & & \\
Sand $(\%)$ & 51.7 & 62.5 & 52.9 \\
$\quad 0.05<D<2 \mathrm{~mm}$ & & & \\
$\mathrm{CEC}\left(\mathrm{meq}^{2}\right.$ per $\left.100 \mathrm{~g}\right)$ & 7.9 & 20.3 & 12.6 \\
$\mathrm{~N}_{\text {total }}(\%)$ d.w. & 0.02 & 0.05 & 0.01 \\
$\mathrm{P}\left(\mathrm{mg} \mathrm{kg}{ }^{-1}\right.$ ) & 14.3 & 21.9 & 11.2 \\
$\mathrm{~K}\left(\mathrm{mg} \mathrm{kg}{ }^{-1}\right.$ ) & 160.8 & 91.2 & 134.5 \\
Mean CFU per g dry soil & $1.20 \mathrm{E}+06$ & $5.70 \mathrm{E}+05$ & $2.90 \mathrm{E}+06$ \\
$\quad(\mathrm{SD})$ & & & \\
\hline
\end{tabular}

Gas chromatographic (GC) analysis was carried out on a Varian 3800 gas chromatograph (Walnut Creek, CA, USA) equipped with a PFPD and capillary column (DB-17, $15.0 \mathrm{~m} \times 0.25 \mathrm{~mm}$ ID, $0.25-\mu \mathrm{m}$ film thickness), using nitrogen carrier gas at a flow rate of $1.5 \mathrm{~mL} \mathrm{~min}^{-1}$. The GC temperature program was initially held at $150^{\circ} \mathrm{C}$ for $2 \mathrm{~min}$, ramped to $280^{\circ} \mathrm{C}$ at a rate of $15^{\circ} \mathrm{C} \mathrm{min}^{-1}$, and held for $20 \mathrm{~min}$. The GC injector was set to $270^{\circ} \mathrm{C}$. The $1-\mu \mathrm{L}$ extracts were injected onto the GC column in a pulsed splitless mode.

The method validation followed the Ministry of Agriculture, People's Republic of China guidelines on quality control procedures for pesticide residues analysis. All validation experiments were performed using blank samples of untreated watermelon, apple and soil.

Linearity was performed by analyzing spiked difenoconazole at six concentration levels between 0.01 and $10 \mathrm{mg} / \mathrm{kg}$. The method was assessed with recovery experiments for watermelon, apple and soil $(\mathrm{n}=5)$ at three spiking concentrations $(0.001,0.01$, and $0.1 \mathrm{mg} / \mathrm{kg})$. The limits of detection (LOD) and quantification (LOQ) were calculated as the concentration of each analyte that produce a chromatographic peak with signal/noise ratio of 3 and 10 , respectively. All the calculations for statistical analysis were performed by using the Matlab 7.0.

Simple first-order kinetics (SFO) model was used to analyze residual data. This model assumes that the change in chemical concentration over time $\left(d C_{t} / d t\right)$ is related to its concentration at that time and a rate constant $\mathrm{k}$.

$\frac{d C_{t}}{d t}=-k t$

Thus, integrating the equation, the concentration at time $t$ after spiking, $C_{t}$ can be expressed as: 
$C_{t}=C_{0} e^{-k t}$

where $C_{0}$ is the initial concentration. According to OECD guideline 307 , the first-order model is to be favoured for interpretation of the data unless its determination coefficient, $r^{2}$, is below 0.7 (OECD 2002). The time at which the concentration reaches half of the initial concentration is referred to DT50 (Eq. 3), while the time for $90 \%$ dissipation of ivermectin $\left(\mathrm{DT}_{90}\right)$ was calculated as given in Eq. 4.

$\mathrm{DT}_{50}=\frac{\ln 2}{k}$

$\mathrm{DT}_{90}=\frac{\ln 10}{k}$

\section{Results and Discussions}

Standard calibration curve of difenoconazole was constructed by plotting the analyte concentration against peak areas $(0.01-10 \mathrm{mg} / \mathrm{kg}, \mathrm{n}=5)$. The standard curve equation was $y=607750 x-55094\left(R^{2}=0.9996\right)$.

Recoveries of difenoconazole in apples and soils were $88.7 \%-104.1 \%$ and $91.9 \%-97.4 \%$, respectively. LOD and LOQ of difenoconazole were 0.0002 and $0.001 \mathrm{mg} / \mathrm{kg}$, respectively.

The experiment errors include random and system errors, they related to many phases, such as the adhesion ability of different crop species, human factors, sampling methods and meteorological conditions, etc.

In this study, the adhesion ability of difenoconazole in different apple species was tested. Four kinds of apples, namely Changfu4, Red fuji, Golden delicious and Red star, which were the common apple species in Chinese market were used. The four kind's apples were immersed in same concentration of pesticide water solutions at about $3 \mathrm{~s}$, and then hang them to dry. Residues of such treatments were analyzed; results showed that RSD\% between them was higher than $5 \%$. The differences which caused by human elements was tested as well. In Daxing (Beijing), four people were randomly selected from our laboratory with different sex, height and weight. A same concentration of pesticide water solution was applied on the same species of apple trees with the same type of apparatuses (Jacto HD400). Although spraying was done as uniformly as possible, the RSD\% of residues between all eight apple trees (two trees for each person) was as high as $10-34.7 \%$, while RSD\% of residues on a bunch to bunch basis within a single apple tree was as high as $208.7 \%$. Recommended in "Standard operating procedures on pesticide registration residue field trials", which edited by Institute for the Control of Agrochemicals, Ministry of Agriculture (ICAMA), the sampling amount of apples was $2 \mathrm{~kg}$. In our test, increasing the sampling amount from 12 (more than $2 \mathrm{~kg}$ for all) to 30 apples (more than $5 \mathrm{~kg}$ for all), the $\mathrm{RSD} \%$ in a single apple tree was significantly decreased to less than 5\%; however, the RSD\% between apple trees was still kept above $10 \%$.

MRL of difenoconazole for apples differed from country to country. It is $1.0 \mathrm{mg} / \mathrm{kg}$ in Japan and Korea, but $0.5 \mathrm{mg} / \mathrm{kg}$ in China. For this study, considering the factors of the food safety, $0.5 \mathrm{mg} / \mathrm{kg}$ was chosen as the MRL value in the terminal residue experiments.

As shown in Table 2, the PHIs at different dosages and frequencies of application were similar in one place, but different from places to places. Considering the possibilities that the different species, different application frequencies and different application dosages could induce different residues, we recommend the PHI for apples is 7 days.

The dissipation behavior of difenoconazole in watermelons and apples in six cities of China over time period of 2008 were shown in Fig. 1. It was found that the dissipation was faster initially and slowed down with the passage of time. Similar kinetics of difenoconazole had been observed in grapes by Banerjee (2008).

Considering the analysis of experiment errors which mentioned above, it was not surprised that difenoconazole showed mutative initial deposits in different places $\left(C_{0}\right.$ in Tables 3, 4), which was $0.29 \mathrm{mg} / \mathrm{kg}$ in Xiaoxian, $0.38 \mathrm{mg} /$ $\mathrm{kg}$ in Daxing and $0.26 \mathrm{mg} / \mathrm{kg}$ in Hangzhou. $\mathrm{DT}_{50}$ and $\mathrm{DT}_{90}$

Table 2 PHIs of difenoconazole in apples

\begin{tabular}{llll}
\hline Application frequencies (times) & Xiaoxian & Daxing & Hangzhou \\
\hline 3 & 6 & 6 & 5 \\
4 & 6 & 7 & 5 \\
\hline
\end{tabular}

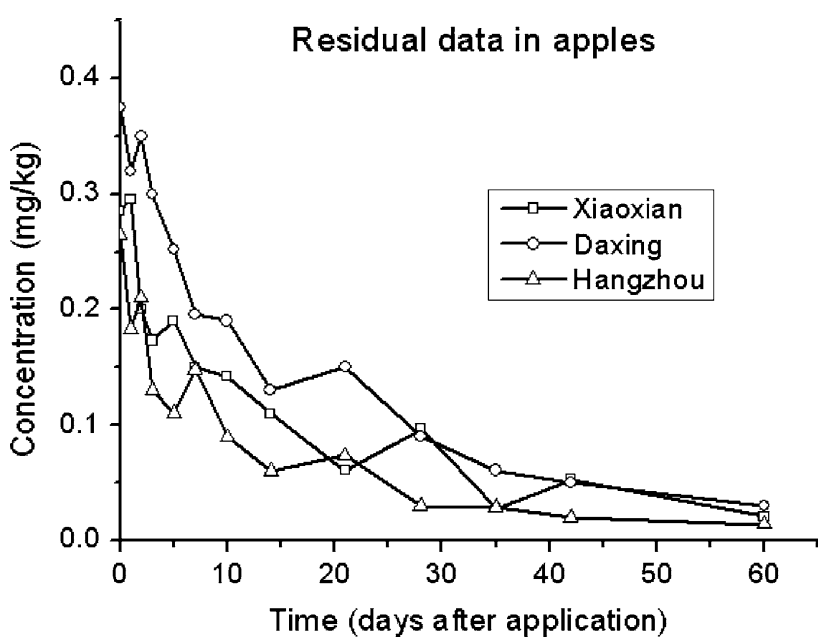

Fig. 1 Residual data of difenoconazole in apples 
Table 3 Parameters of difenoconazole dissipation in apples

\begin{tabular}{lccc}
\hline Parameters & Xiaoxian & Daxing & Hangzhou \\
\hline$C_{0}$ & 0.258 & 0.351 & 0.220 \\
$k$ & 0.058 & 0.055 & 0.081 \\
$r^{2}$ & 0.898 & 0.957 & 0.894 \\
$\mathrm{DT}_{50}$ & 10.2 & 11.4 & 6.3 \\
$\mathrm{DT}_{90}$ & 37.8 & 40.6 & 26.2 \\
\hline
\end{tabular}

Table 4 Parameters of difenoconazole dissipation in soils

\begin{tabular}{lccc}
\hline Parameters & Xiaoxian & Daxing & Hangzhou \\
\hline$C_{0}$ & 0.787 & 0.646 & 0.789 \\
$k$ & 0.020 & 0.045 & 0.011 \\
$r^{2}$ & 0.881 & 0.766 & 0.963 \\
$\mathrm{DT}_{50}$ & 29.8 & 9.6 & 68.4 \\
$\mathrm{DT}_{90}$ & 108.7 & 45.6 & 216.3 \\
\hline
\end{tabular}

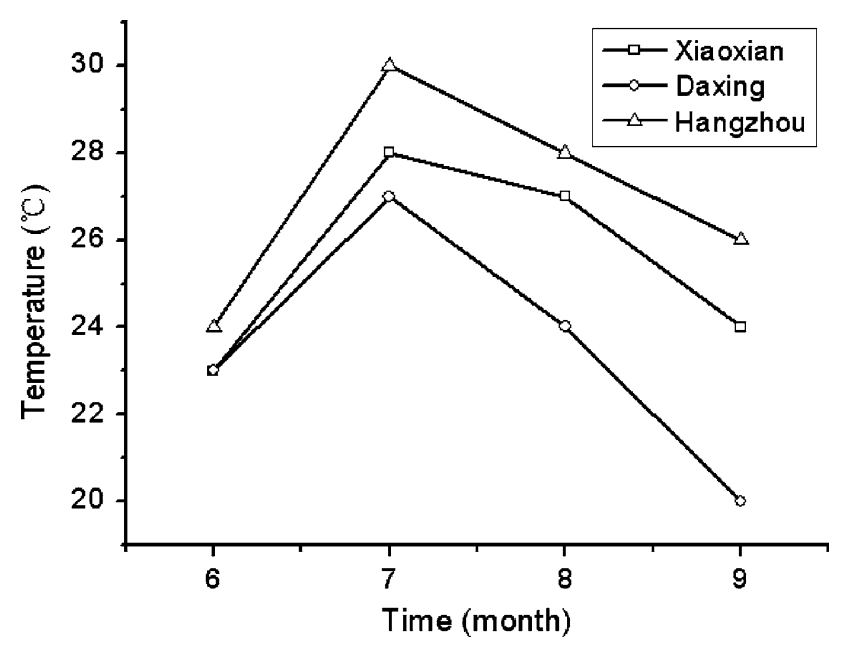

Fig. 2 Mean temperature of experiment plots during field trial process of the three places

of apples in different regions were in the range of 4.6-11.4 and 26.2-81.7 days, respectively.

Temperatures and rainfalls of the three places during the experiment time were recorded and shown in Figs. 2 and 3. Residual data of difenoconazole in soils were shown in Fig. 4.

In this study, the pesticide was applied at the same dosage (100 g a.i./ha) and by the same apparatuses (Jacto HD400) in all three places, however, different initial concentrations of difenoconazole appeared in different soils. In the reports of Fredlund (1994), Terry and Hutson (1999), the higher permeability of sand soils and the translaminar movement of difenoconazole decreased the initial concentration of difenoconazole in soils. In this paper, the similar situation was detected in Daxing (sand content rate

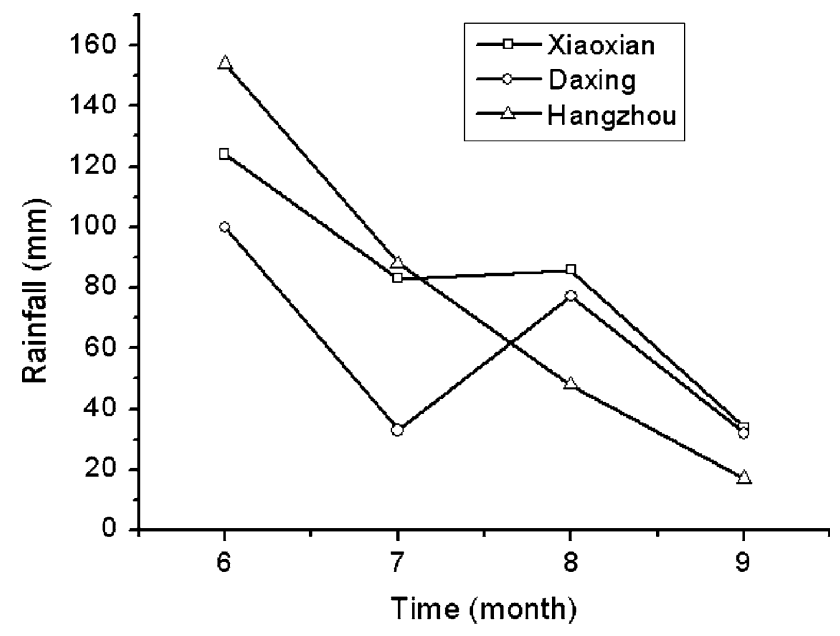

Fig. 3 Monthly rainfall of experiment plots during field trial process of the three places

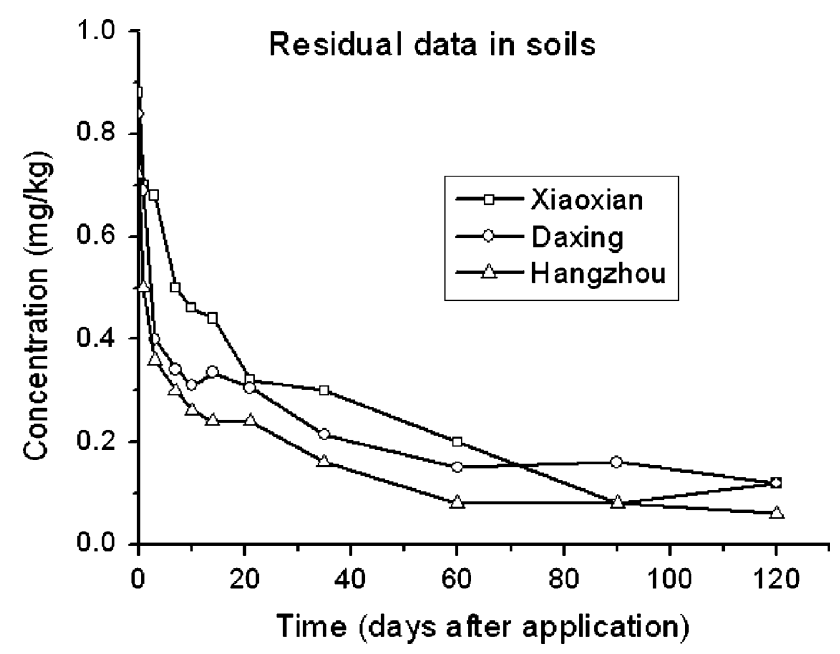

Fig. 4 Residual data of difenoconazole in soil

was $62.5 \%$ and the initial concentration was $0.755 \mathrm{mg} / \mathrm{kg}$ ) and Hangzhou (sand content rate was 52.9\% and the initial concentration was $0.718 \mathrm{mg} / \mathrm{kg}$ ), the initial concentration decreased with the increasing of sand content rate.

In our test, we found that higher temperatures possessed higher dissipation rate (Fig. 2; Tables 3, 4). Similar reports about the relationships between the temperatures and the dissipation rates of pesticide were also observed by many authors (Maria and Lennart 2007; José et al. 2009).

\section{References}

Banerjee K, Oulkar DP, Patil SH, Dasgupta S, Adsule PG (2008) Degradation kinetics and safety evaluation of tetraconazole and difenoconazole residues in grape (Vitis vinifera L.). Pest Manage Sci 64(3):283-289 
Ellen T, Ottw JCG, Gero B (1997) Degradation of the fungicide difenoconazole in a silt loam soil as affected by pretreatment and organic amendment. Environ Pollut 96:409-414

Fredlund DG, Xing A, Huang SY (1994) Predicting the permeability function for unsaturated soils using the soil-water characteristic curve. Can Geotech J 31:521-532

Jacob R, Werner S (1996) Residues of difenoconazole and penconazole on apple leaves and grass and soil in an apple orchard in north-eastern Switzerland. J Crop Prot 15:27-31

José F, Encarnación R, Pilar H, Alfredo L, Pilar F (2009) Dissipation rates of insecticides and fungicides in peppers grown in greenhouse and under cold storage conditions. Food Chem 113:727-732

Maria PC, Lennart T (2007) Effect of biobed composition, moisture, and temperature on the degradation of pesticides. J Agric Food Chem 55:5725-5733
OECD, 2002. OECD guideline for testing of chemicals No. 307. aerobic and anaerobic transformation in soil, Paris

Philippe T, Christian C, MZ ERIC (2007) Pesticide residues in heterogeneous plant populations, a model-based approach applied to nematicides in banana (Musa spp.). J Agric Food Chem 55:2504-2508

Terry R, Hutson D (1999) Metabolic pathways of agrochemical. Part two: insecticide and fungicide. The Royal Society of Chemistry, UK

Walker A, Jurado EM, Bending GD, Smith VJR (2001) Spatial variability in the degradation rate of isoproturon in soil. Environ Pollut 111:407-415

Wang ZH, Yang T, Qin DM, Gong Y, Ji Y (2008) Determination and dynamics of difenoconazole residues in Chinese cabbage and soil. Chinese Chem Lett 19:969-972 